\title{
Factors Associated with Need for Drainage of Pleural Effusion after Diaphragm Surgery
}

\author{
Rachel M. Whynott, Nauman Khurshid, Seema Nayak, Kelly J. Manahan, John P. Geisler* \\ Athens Regional Health Services, Division of Gynecologic Oncology, Department of Obstetrics and Gynecology, \\ University of Georgia/Georgia Regents University, Athens, USA \\ Email: "Geisler.jp@gmail.com
}

Received 17 April 2014; revised 15 May 2014; accepted 22 May 2014

Copyright (C) 2014 by authors and Scientific Research Publishing Inc.

This work is licensed under the Creative Commons Attribution International License (CC BY). http://creativecommons.org/licenses/by/4.0/

(c) $\underset{\mathrm{EY}}{\mathrm{EY}}$ Open Access

\section{Abstract}

Background: Diaphragm surgery is common with advanced ovarian malignancies. The purpose of this study is to determine associated factors with the need for drainage of pleural effusion after diaphragm surgery. Methods and Materials: A retrospective chart review was undertaken in all women undergoing debulking surgery for stage IIIc/IV ovarian cancer from 2007-2009. Results: One hundred and eight patients were found to be eligible for the study, but 73 were the primary focus of this paper due to having undergone debulking surgery, including diaphragmatic surgery, from 2007-2009. All 73 had ablation with the argon beam coagulator, 7 had a full thickness resection, and 7 had extensive peritoneal peel. Five patients had preoperative effusions. Only 7 patients required chest drainage postoperatively. Pre-operative ascites correlated closely with postoperative effusion ( $p$-value $=0.031$ ) but not with drainage $(p$-value $=0.068)$. The mean age of patients requiring drainage was significantly older (73 years) than that of patients who did not require drainage $(60$ years) ( $p$-value $=\mathbf{0 . 0 0 2}$ ). Conclusion: Older patients undergoing diaphragm surgery are more likely to require chest tube or thoracentesis due to concurrent symptoms. Pre-operative ascites correlates closely with the development of postoperative effusion after diaphragm surgery.

\section{Keywords}

Pleural Drainage, Diaphragm Surgery, Ovarian Cancer

\section{Introduction}

Primary cytoreductive surgery followed by adjuvant chemotherapy remains the most accepted method of management of ovarian cancer, with the goal of no residual cancer after the procedure [1] [2]. The majority of pa-

\footnotetext{
${ }^{*}$ Corresponding author.
}

How to cite this paper: Whynott, R.M., Khurshid, N., Nayak, S., Manahan, K.J. and Geisler, J.P. (2014) Factors Associated with Need for Drainage of Pleural Effusion after Diaphragm Surgery. Journal of Cancer Therapy, 5, 680-684. 
tients with ovarian cancer present in FIGO stage III or IV, and most patients are offered this management. This procedure often includes upper abdominal surgery to reduce tumor burden. Ovarian cancer cells travel along with peritoneal fluid, and during its clockwise movement, the cancer cells may get deposited in the upper abdomen. Because of this, the right hemidiaphragm is a common place to find ovarian cancer [3]. There are several different methods to rid the diaphragm of disease, including diaphragmatic ablation (DA), diaphragmatic resection (DR), and peritoneal peel or peritonectomy (PP).

Cytoreductive surgery including the diaphragm and upper abdomen is feasible with good success [3] [4]. However, upper abdominal surgery, specifically diaphragmatic surgery, is associated with some morbidity [3] [5]. A common postoperative morbidity encountered is the development of pleural effusion. Another relatively known morbidity is pneumothorax. Postoperative pleural effusion is usually seen within a few days of surgery. Effusions may present as dyspnea, decreased pulse oximetry, and decreased breath sounds on the affected side. Computed tomographic scan or a plain chest radiograph is usually diagnostic. Management of pleural effusion may require drainage using thoracentesis or a chest tube if the patient is symptomatic.

Currently, there is no consensus as to whether all the patients undergoing radical debulking, including diaphragmatic surgery, require a prophylactic chest tube placement in the operating room. There is also no consensus on whether or not scans should be performed in postoperative asymptomatic patients. To address the need for prophylactic chest tubes, we undertook a retrospective analysis looking at the outcomes and morbidity following diaphragmatic surgery in our gynecologic cancer population.

\section{Methods and Materials}

This study was approved by the institutional review board. All patients with ovarian, fallopian tube, or primary peritoneal cancer undergoing primary debulking surgery from January 2007 through December 2009 were retrospectively analyzed, totaling 108. Patients undergoing diaphragmatic surgery were the primary focus of this analysis. No patients were knowingly excluded. We defined diaphragmatic surgery as diaphragmatic resection (Figure 1), diaphragmatic ablation and/or diaphragmatic peel/peritonectomy of the diaphragm.

Seventy three patients were identified to meet the above criteria. Charts on all 108 patients were then analyzed for demographic data, stage of cancer, histological type of cancer, type of surgery, extent of surgery, tumor burden after surgery, preoperative pleural effusion, preoperative CA125, prealbumin level, postoperative evidence of pleural effusion (confirmed by radiological testing), use of thoracentesis or chest tube placements, and postoperative complications. All pulmonary complications were attributed to the surgery. All postoperative pleural effusions were radiologically confirmed. The decision to ablate, peel, or resect the diaphragm was made by the attending gynecologic oncologist at the time of surgery.

\section{Results}

One hundred eight patients underwent primary debulking surgery, and the 73 patients who underwent primary cytoreductive surgery including diaphragmatic surgery were analyzed. Demographic characteristics of all patients undergoing primary surgery are shown in Table 1.

The mean age in years of patients undergoing diaphragm surgery was 61 , with median of 63 . The mean preoperative CA 125 was $564 \mathrm{IU} / \mathrm{dl}$ and the median was $189 \mathrm{IU} / \mathrm{ml}$. The mean of the preoperative prealbumin was $16 \mathrm{mg} / \mathrm{dl}$ and the median was $14 \mathrm{mg} / \mathrm{dl}$. Five of the 7 patients requiring chest drainage had documented preoperative effusion. The average patient undergoing diaphragm surgery was obese, with a mean BMI of $34 \mathrm{~kg} / \mathrm{m}^{2}$ and a median of $32 \mathrm{~kg} / \mathrm{m}^{2}$. Preoperative ascites correlated with postoperative effusion (p-value $=0.031$ ), but not with the need for drainage ( $\mathrm{p}$-value $=0.068$ ). The mean age of patients requiring drainage was significantly older (73 years) than those not requiring it (60 years) ( $p$-value $=0.002$ ). There was no correlation between postoperative effusion and the extent of diaphragm surgery. There was also no correlation between performance of other upper abdominal surgery (liver resection, splenectomy, gastrectomy, pancreatectomy) and postoperative effusion.

Seventy-three of 108 patients undergoing primary surgical debulking had diaphragmatic ablation of a portion of the diaphragm with the argon beam coagulator, 7 patients (9.5\% of the 73) had full thickness diaphragmatic resection, and 7 patients (9.5\%) had a diaphragm peel/peritonectomy. Table 2 documents the differences in survival and other characteristics between those who underwent diaphragm surgery and those who did not. During the debulking procedures, $27.4 \%$ of those undergoing diaphragm surgery had colon resection while $12.3 \%$ patients had small bowel resection, compared to $17.1 \%$ and $8.6 \%$ of those not requiring diaphragm surgery (p 


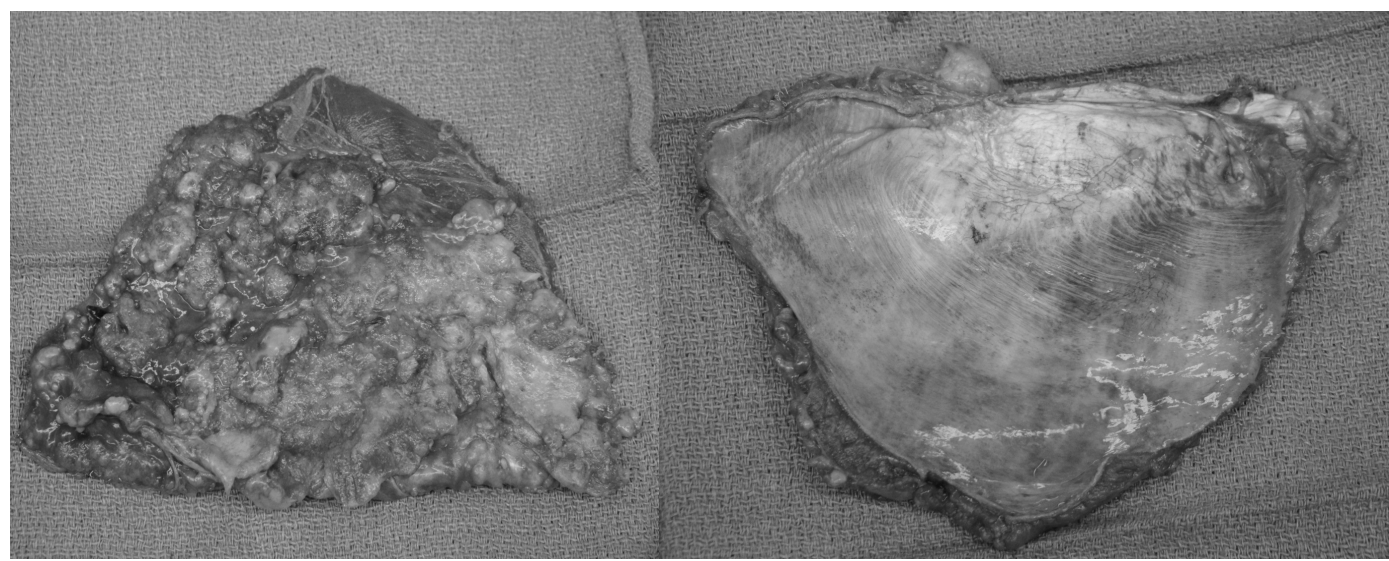

Figure 1. Left side show a $10 \mathrm{~cm}$ (maximal diameter) piece of the diaphragm looking at the peritoneal surface. The right side of the figure shows the same piece of resected diaphragm from the pleural surface. The defect was closed primarily with 2-0 polydioxanone suture on a taper needle and a post-operative chest tube was not needed.

Table 1. Demographic characteristics.

\begin{tabular}{cccc}
\hline & No diaphragm surgery required & Diaphragm surgery required & p value \\
\hline Age & 60 & 61 & 0.55 \\
BMI kg/m & 33 & 34 & 0.79 \\
CA 125 IU/ML & 709 & 564 & 0.65 \\
Prealbumin & 15.9 & 16.2 & 0.80 \\
\hline
\end{tabular}

Table 2. Correlation with diaphragm surgery.

\begin{tabular}{cccc}
\hline & No diaphragm surgery required & Diaphragm surgery required & p value \\
\hline Alive at 50 months & $68.6 \%$ & $71.2 \%$ & 0.78 \\
Ascites & $60.0 \%$ & $59.0 \%$ & 0.91 \\
Pre-operative effusion & $5.7 \%$ & $6.8 \%$ & 0.82 \\
Post-operative effusion & $65.7 \%$ & $68.5 \%$ & 0.77 \\
Chest drainage required & $5.7 \%$ & $9.6 \%$ & 0.50 \\
Small bowel resection & $8.6 \%$ & $12.3 \%$ & 0.89 \\
Colon resection & $17.1 \%$ & $27.4 \%$ & 0.24 \\
\hline
\end{tabular}

value $=0.24$ and 0.89 , respectively). All 108 patients $(100 \%)$ were optimally cytoreduced at the end of the primary surgery. Preoperative effusion was identified in 5 (6.8\%) patients while postoperative effusion was diagnosed in $68.5 \%$ patients. Forty-three (59\%) had ascites preoperatively. Seven (9.6\%) patients had drains placed postoperatively for treatment of pleural effusions after diaphragm surgery compared to $5.7 \%$ not requiring diaphragm surgery.

\section{Discussion}

Primary optimal cytoreduction before chemotherapy has been shown to improve survival in patients with advanced ovarian cancer [1]-[3]. The right hemidiaphragm has been shown to be a common site for metastases in the upper abdomen in women with advanced ovarian cancer [6] [7]. Upper diaphragmatic surgery has been described in detail [8]-[13]. It has been shown to be safe and to help improve long-term outcome. This is due to the decreased tumor burden at the end of the case [14]. Remarkably, however, according to a Society of Gynecologic Oncologists' survey, $76 \%$ of the gynecologic oncologists queried stated that diaphragmatic disease was a barrier to complete cytoreduction [14]. There is increasing evidence that diaphragmatic surgery can be per- 
formed with acceptable morbidity and mortality.

Pleural effusion is one of the most common postoperative complications after diaphragmatic surgery. Liver mobilization alone appears to be a reason for pleural effusion. Other causes include full thickness diaphragmatic resection, diaphragmatic ablation, and peritoneal peel [15] [16]. There is still debate whether to place a chest tube before or during surgery to avoid postoperative complications [17] [18]. Tsolakidis et al. stated that patients who had chest tubes placed intraoperatively subjectively felt better due to absence of dyspnea [19]. The tubes remained in place 5 - 10 days after surgery. Regarding the use of chest tube or thoracentesis in their series, only 1 (3\%) patient required chest tube (coagulation group) drainage for 19 days and the other 3 patients (9\%) underwent thoracentesis. On the contrary, in the group undergoing more extensive diaphragm procedures, 7 (24\%) chest tube drains were required for approximately 11 days (5 - 48), 2 of them for severe pneumothorax, and another 5 (16\%) patients needed thoracentesis. Although Chereau et al. and Cliby both recommended the use of prophylactic chest tube placement, they concluded that this approach still needs further evaluation [8] [19]. The relatively low rate of thoracentesis or pleural effusion drainage (9.5\%) concurs with other studies. The rate of pleural effusion is significantly high $(40 \%-60 \%)$ in diaphragmatic surgery patients; however, placing chest tubes on every patient after diaphragmatic surgery would increase the morbidity of the procedure overall. Our study indicates that whether or not a patient undergoes diaphragm surgery, the rate of symptomatic effusion requiring drainage is below 10\% (Table 2). Significantly, patients requiring drainage were over a decade older than those who did not require drainage (Table 2).

Seneff et al. showed that out of 125 thoracenteses performed, $11 \%$ had pneumothorax as a major complication of the procedure while $22 \%$ had severe pain as a minor complication [20]. The largest study currently for diaphragmatic surgery (89 patients) by Tsolakidis et al. showed that the incidence of pleural effusion was 52.8\% and chest tube in only $13 \%$ of patients [14]. In his follow-up study, Tsolakidis showed that less extensive procedures were needed for the diaphragm in women undergoing an interval cytoreduction compared to a primary cytoreduction [21].

Although the pleural space is always violated in a full thickness resection of the diaphragm, a persistent pneumothorax is not common. This is due to two reasons. First, it is a common surgical technique to drain the pneumothorax with the patient under positive pressure ventilation as the diaphragm is closed. Second, and probably more importantly, there is normally no violation of the lung parenchyma during a diaphragm resection. Therefore, there is not a persistent air leak into the space once the diaphragm is closed. Hence, this is a reason not to place a chest tube.

Although chest tube placement on patients undergoing diaphragm surgery remains debatable, the literature clearly demonstrates the advantages of complete cytoreduction including diaphragm surgery. With less morbidity associated with diaphragmatic surgery, the authors strongly suggest that all patients undergoing cytoreductive surgery should be evaluated and treated for upper abdominal disease. This is evidenced by over $70 \%$ of patients surviving alive with a median follow-up of over 50 months. Diaphragm disease should not be a reason that a patient cannot undergo optimal or complete cytoreduction.

\section{References}

[1] Chi, D.S., Franklin, C.C., Levine, D.A., Akselrod, F., Sabbatini, P., Jarnagin, W.R., DeMatteo, R., Poynor, E.A., AbuRustum, N.R. and Barakat, R.R. (2004) Improved Optimal Cytoreduction Rates for Stages IIIC and IV Epithelial Ovarian, Fallopian Tube, and Primary Peritoneal Cancer: A Change in Surgical Approach. Gynecologic Oncology, 94, 650654. http://dx.doi.org/10.1016/j.ygyno.2004.01.029

[2] Chang, S.J., Bristow, R.E. and Ryu, H.S. (2012) Impact of Complete Cytoreduction Leaving No Gross Residual Disease Associated with Radical Cytoreductive Surgical Procedures on Survival in Advanced Ovarian Cancer. Annals of Surgical Oncology, 19, 4059-4067. http://dx.doi.org/10.1245/s10434-012-2446-8

[3] Eisenkop, S.M. and Spirtos, N.M. (2001) Procedures Required to Accomplish Complete Cytoreduction of Ovarian Cancer: Is There a Correlation with “Biological Aggressiveness” and Survival? Gynecologic Oncology, 82, 435-441. http://dx.doi.org/10.1006/gyno.2001.6313

[4] Zapardiel, I., Peiretti, M., Zanagnolo, V., Biffi, R., Bocciolone, L., Landoni, F., Aletti, G., Colombo, N. and Maggioni, A. (2011) Diaphragmatic Surgery during Primary Cytoreduction for Advanced Ovarian Cancer: Peritoneal Stripping versus Diaphragmatic Resection. International Journal of Gynecological Cancer, 21, 1698-1703. http://dx.doi.org/10.1097/IGC.0b013e31822f65c3

[5] Rafii, A., Stoeckle, E., Jean-Laurent, M., Ferron, G., Morice, P., Houvenaeghel, G., Lecuru, F., Leblanc, E. and Quer- 
leu, D. (2012) Multi-Center Evaluation of Post-Operative Morbidity and Mortality after Optimal Cytoreductive Surgery for Advanced Ovarian Cancer. PLoS ONE, 7, Article ID: e39415. http://dx.doi.org/10.1371/journal.pone.0039415

[6] Tan, D.S., Agarwal, R. and Kaye, S.B. (2006) Mechanisms of Transcoelomic Metastasis in Ovarian Cancer. Lancet Oncology, 7, 925-934. http://dx.doi.org/10.1016/S1470-2045(06)70939-1

[7] Griffiths, C.T. and Finkler, N. (1992) Surgery for Carcinoma of Ovary: Extrapelvic Cytoreduction. In: Coppleson, M., Ed., Gynecologic Oncology, 2nd Edition, Churchill Livingstone, London, 1325-1333.

[8] Cliby, W., Dowdy, S., Feitoza, S., Gostout, B. and Podratz, K. (2004) Diaphragm Resection for Ovarian Cancer: Technique and Short-Term Complications. Gynecologic Oncology, 94, 655-660. http://dx.doi.org/10.1016/j.ygyno.2004.04.032

[9] Dowdy, S.C., Loewen, R.T., Aletti, G., Feitoza, S.S. and Cliby, W. (2008) Assessment of Outcomes and Morbidity Following Diaphragmatic Peritonectomy for Women with Ovarian Carcinoma. Gynecologic Oncology, 109, 303-307. http://dx.doi.org/10.1016/j.ygyno.2008.02.012

[10] Chi, D.S., Eisenhauer, E.L., Zivanovic, O., Sonoda, Y., Abu-Rustum, N.R., Levine, D.A., Guile, M.W., Bristow, R.E., Aghajanian, C. and Barakat, R.R. (2009) Improved Progression-Free and Overall Survival in Advanced Ovarian Cancer as a Result of a Change in Surgical Paradigm. Gynecologic Oncology, 114, 26-31. http://dx.doi.org/10.1016/j.ygyno.2009.03.018

[11] Silver, D.F. (2004) Full-Thickness Diaphragmatic Resection with Simple and Secure Closure to Accomplish Complete Cytoreductive Surgery for Patients with Ovarian Cancer. Gynecologic Oncology, 95, 384-387. http://dx.doi.org/10.1016/j.ygyno.2004.07.046

[12] Eisenhauer, E., Abu-Rustum, N., Sonoda, Y., Levine, D., Poynor, E., Aghajanian, C., et al. (2006) The Addition of Extensive Upper Abdominal Surgery to Achieve Optimal Cytoreduction Improves Survival in Patients with Stages IIIC-IV Epithelial Ovarian Cancer. Gynecologic Oncology, 103, 1083-1090.

http://dx.doi.org/10.1016/j.ygyno.2006.06.028

[13] Montz, F., Schlaerth, J. and Berek, J. (1989) Resection of Diaphragmatic Peritoneum and Muscle: Role in Cytoreductive Surgery of Ovarian Cancer. Gynecologic Oncology, 35, 338-340. http://dx.doi.org/10.1016/0090-8258(89)90074-7

[14] Tsolakidis, D., Amant, F., Van Gorp, T., Leunen, K., Neven, P. and Vergote, I. (2010) Diaphragmatic Surgery during Primary Debulking in 89 Patients with Stage IIIB-IV Epithelial Ovarian Cancer. Gynecologic Oncology, 116, 489-496. http://dx.doi.org/10.1016/j.ygyno.2009.07.014

[15] Fanfani, F., Fagotti, A., Gallotta, V., Ercoli, A., Pacelli, F., Costantini, B., Vizzielli, G., Margariti, P.A., Garganese, G. and Scambia, G. (2010) Upper Abdominal Surgery in Advanced and Recurrent Ovarian Cancer: Role of Diaphragmatic Surgery. Gynecologic Oncology, 116, 497-501. http://dx.doi.org/10.1016/j.ygyno.2009.11.023

[16] Eisenhauer, E.L., D’Angelica, M.I., Abu-Rustum, N.R., Sonoda, Y., Jarnagin, W.R., Barakat, R.R. and Chi, D.S. (2006) Incidence and Management of Pleural Effusions after Diaphragm Peritonectomy or Resection for Advanced Mullerian Cancer. Gynecologic Oncology, 103, 871-877. http://dx.doi.org/10.1016/j.ygyno.2006.05.023

[17] Aletti, G., Dowdy, S., Podratz, K. and Cliby, W. (2006) Surgical Treatment of Diaphragm Disease Correlates with Improved Survival in Optimally Debulked Advanced Stage Ovarian Cancer. Gynecologic Oncology, 100, $283-287$. http://dx.doi.org/10.1016/j.ygyno.2005.08.027

[18] Vergote, I., Marquette, S., Amant, F., Barteloot, P. and Neven, P. (2005) Port-Site Metastases after Open Laparoscopy: A Study in 173 Patients with Advanced Ovarian Carcinoma. International Journal of Gynecological Cancer, 15, 776779. http://dx.doi.org/10.1111/j.1525-1438.2005.00135.x

[19] Chereau, E., Ballester, M., Selle, F., Cortez, A., Pomel, C. and Darai, E. (2009) Pulmonary Morbidity of Diaphragmatic Surgery for Stage III/IV Ovarian Cancer. British Journal of Obstetrics and Gynaecology, 116, 1062-1068. http://dx.doi.org/10.1111/j.1471-0528.2009.02214.x

[20] Seneff, M.G., Corwin, R.W., Gold, L.H. and Irwin, R.S. (1986) Complications Associated with Thoracocentesis. Chest, 90, 97-100. http://dx.doi.org/10.1378/chest.90.1.97

[21] Tsolakidis, D., Amant, F., Leunen, K., Cadron, I., Neven, P. and Vergote, I. (2011) Comparison of Diaphragmatic Surgery at Primary or Interval Debulking in Advanced Ovarian Carcinoma: An Analysis of 163 Patients. European Journal of Cancer, 47, 191-198. http://dx.doi.org/10.1016/j.ejca.2010.08.020 